\title{
Determination of Phenytoin in Human Plasma by a Validated HPLC Method: Application to Therapeutic Drug Monitoring Study Running title: Measurement of phenytoin in plasma by a novel HPLC method
}

\author{
Emrah Dural ${ }^{1^{*}}$, Aslı Bolayır² ${ }^{2}$ Burhanettin Çiğgem² \\ 1 Department of Pharmaceutical Toxicology, Faculty of Pharmacy, Sivas Cumhuriyet University, Sivas, Turkey \\ 2Department of Neurology, Faculty of Medicine, Sivas Cumhuriyet University, Sivas, Turkey
}

\begin{abstract}
The aim of this study was to develop a simple and reliable HPLC method for the determination of phenytoin (PHT) in human plasma. Accuracy (RE\%) were determined between (-0.93\%) to $2.49 \%$ and precision (RSD\%) values was $\leq 7.94$. The quantitation limit was $3.54 \mu \mathrm{g} / \mathrm{mL}$ and recovery was found between $82.15 \%$ and 101.06\%. The method was applied to real plasma samples $(\mathrm{n}=7)$. Plasma-PHT levels were found between 1.12 and $18.76 \mu \mathrm{g} / \mathrm{mL}$ (9.52 \pm 7.78, mean $\pm \mathrm{SD}$ ). Both the plasma and dose-rated plasma results of PHT showed so high RSD\% which were between $81.74 \%$ and $89.61 \%$. In addition plasma-PHT levels were outside the recommended treatment range in 4 of the 7 patients (57.14\%) examined, and also surprisingly PHT could not be detected in a patient's plasma. This procedure is relatively simple, precise, and applicable for routine therapeutic drug monitorization of PHT in neurology clinics or toxicological analyses in reference laboratories.
\end{abstract}

Keywords: Phenytoin, Human plasma, Therapeutic drug monitoring, Method validation, HPLC-UV.

\section{Corresponding author:}

Emrah Dural, Associate Professor

Sivas Cumhuriyet University, Faculty of Pharmacy, Department of Pharmaceutical Toxicology 58140, Sivas, Turkey Telephone number: +90 3462191010 (\#3894)

Fax: +90 3462191634

E-mail: emrahdural@cumhuriyet.edu.tr

ORCID

Emrah Dural 0000-0002-9320-8008,

Aslı Bolayır 0000-0001-6566-3751,

Burhanettin Çiğdem 0000-0003-4941-9497.

(Received 08 April 2020, accepted 16 May 2020) 


\section{INTRODUCTION}

Epilepsy which affecting people of all ages is the most common serious neurological disease that statistic studies have shown that, it affects $1 \%$ of the world population ${ }^{1}$ and may cause permanent deformation and reduce quality of life and necessitate expensive treatment ${ }^{2}$. It is a serious, potentially life-threatening brain disease that can successfully treat symptoms in most patients with one or more antiepileptic drugs ${ }^{3}$.

PHT, 5,5-diphenyl-imidazoline-2-4-dione, (Figure 1.a) is one of the most widely used anticonvulsant drug for the treatment of many epileptic-type seizures (grand-mal complex partial seizures), and is usually given orally in doses ranging from 100 to $600 \mathrm{mg} /$ day ${ }^{4}$. Either it can be use to treatment of epilepsy seizures or use for prevent the seizures in patients under the risk ${ }^{5}$. PHT, following the oral ingestion, precipitates in stomach. A good correlation is showed between its plasma concentration and clinical effect ${ }^{6}$. Although peak plasma levels occur 3-12 hours after a single dose, its absorption can be extended up to 2 weeks, especially at large overdose. PHT is highly bounding to plasma proteins (90\%) and free (unbound) PHT is the component that responsible to its pharmacological effect, so any factor that modulates protein binding of PHT is expected to alter free drug levels. The interaction of PHT with other drugs or diseases (e.g., renal failure, uremia) and critical diseases can lead to the observation of plasma levels in which its toxicity may occur by altering its pharmacokinetics and/or efficacy. PHT has poor water solubility and a narrow therapeutic index, so it is very important to achieve equilibrium to avoid pharmacodynamic activity as well as dose-dependent side effects ${ }^{7}$. It is also reported that the enzyme system including PHT metabolism becomes gradually saturated, in which the increase in the PHT dose caused to a decrease in its elimination. That means after the enzyme system becomes saturated with PHT, even a small change in dose could be cause to a big change its plasma levels. PHT concentrations leading to enzyme saturation are highly variable among individuals, therefore, a 50-fold difference in plasma PHT concentration may be observed between patients receiving the same dose. In addition, it stated that PHT may demonstrate non-linear pharmacokinetics even with the therapeutic range ${ }^{5}$. It is excreted by bile as inactive metabolites, which are reabsorbed from the intestinal tract and by urine ${ }^{8}$. Monitoring of PHT plasma levels is clinically so important to achieve and maintain its therapeutic efficacy. Recommended PHT therapeutic serum/plasma concentrations are reported between 10 to 20 $\mu \mathrm{g} / \mathrm{mL}$. Oral exposures are associated predominantly with CNS symptoms, so its common dose-related adverse effects are somnolence, fatigue, dizziness, 
confusion, visual disturbances, nystagmus and ataxia, addditionally, nausea, vomiting and anorexia which are gastrointestinal side effects are also seen. The effects of PHT overdose between $20 \mu \mathrm{g} / \mathrm{mL}$ and $40 \mu \mathrm{g} / \mathrm{mL}$ are far lateral nystagmus, $45^{\circ}$ lateral nystagmus, ataxia and decreased mentation, respectively. When PHT plasma value is reached greater than $100 \mu \mathrm{g} / \mathrm{mL}$, it lethal effect ${ }^{8}$.

Therapeutic drug monitoring (TDM) is a well-established procedure that helps maximize the effectiveness of antiepileptic treatment and minimizes its adverse effects and also increases clinical efficacy. Currently, monitoring of PHT plasma concentrations like to most of other anti epileptic drugs, carried out by commercial immunochemical determination methods. In addition to that imminochemical kits are mostly designed for just an individual drug. Although they can be very sensitive in some applications, unfourtunately they have the crosspositive reaction risk. So they can give false-positive result. For these reasons, the results obtained from drug monitoring of immunochemical methods need to be confirmed by any chromatographic method.

HPLC is a simple, sensitive, accurate and cost-effective method ${ }^{9,10}$ and it gives a good recovery with high precision and also easily accessible in many laboratories since cheaper compare to other techniques ${ }^{11}$. This chromatographic technique used to separate the components in a mixture, to identify each ingredient, and to measure each component. The method includes a liquid sample being passed over a solid adsorbent packed into a column using a flow of liquid solvent known as the mobile phase. Each analyte in the sample interacts with the adsorbent at a different level, which causes a change in the flow of the analytes in the column. If the interaction is strong, the analytes flow off the column in a long amount of time and if the interaction is poor, then the elution time is short ${ }^{11}$. This technique could give excellent results at the identification of many pharmaceuticals. For these reasons, high-performance liquid chromatography (HPLC) has been using as reliable techniques for the determination of PHT and other anticonvulsant drugs.

HPLC coupled with ultraviolet (UV) detection ${ }^{12-18}$, flourescence detection ${ }^{19}$, tandem mass spectrometry (MS-MS) ${ }^{20-23}$; gas chromatography (GC) coupled with mass spectrometry (MS) ${ }^{18,24}$ and capillary electrophoresis (CE) coupled with $\mathrm{UV}^{6}$ are the reported methods that were used for determination of PTH in biological samples. In addition to that, colouremetric based determination methods ${ }^{25}$, radioimmunoassay ${ }^{18}$, enzyme immunoassay (EMIT) ${ }^{18,26}$, fluorescence polarization immunoassay (FPIA) ${ }^{27}$ and spectrophotometric assay ${ }^{18}$ have been often used monitorization of PHT. 
Some extraction tecniques which based on protein precipitation (PPT) ${ }^{12}$, liquidliquid extraction (LLE) ${ }^{13,16,22,23}$, solid-phase extraction (SPE) ${ }^{12,14,16,24}$, solid-phase micro extraction (SPME) ${ }^{28,29}$ has been used for preparation of the biological samples to the PTH analyses. Protein precipitation method is a simple, easier and fast method compare to all of these applications. It needs moderate amount solvent and short spin-down step and generally after these steps, supernatant/ resulting extract can be apply to the HPLC that desired amount. In addition to this, some apllications needs to filtration of the samples. However, there is a risk that the extract obtained may block the column if the method is not well established. Also, obtained chromatograms applied this tecnique usually shows very high backround that is exactly so important for selectivity and specificity of the method. LLE is often preferred in the monitoring of many pharmaceuticals. It is a technique in which the matrix $\mathrm{pH}$ of the solvents to be used in the application can be adjusted according to analytes and application ${ }^{30}$. After evaporation of the solvent obtained at the end of the application, the residue can be analyzed by reconstitution in the appropriate solvent. Extraction recovery values are sufficient for drug analysis from biological samples. Also, resulting extract product may be transferred, evaporated to dryness and reconsituted with a suitable solvent prior the analysis. But in this technique usually, a high volume of solvents consume which has toxic properties. In addition, the LLE application has multiple steps, each of which takes a long time. SPME was introduced as a solvent-free process that may use different types liquid samples. Although, it has important properties, techniques need to expensive fibers that rather sensitive complex matrix like to plasma. However, protein precipitation method is a simple and fast method compare to all of these applications. It needs moderate amount solvent and short spin-down step and generally after these two steps, supernatant/resulting extract can be apply to the HPLC that desired amount. SPE is a selective sample preparation method that uses a packet solid sorbent (silica or polymer) to isolate the desire analyte, that compare to LLE, less amount solvent which may toxic uses in SPE. However, the price of adsorbents needed in this technique is expensive, leading to an increase in the cost per analysis. Although the price of commercial adsorbents needed in this technique is expensive, the recovery efficiency obtained is quite successful. In the samples obtained using this method, validation test results, especially accuracy and precision, are generally quite successful. In addition, many natural-plant materials and synthetic products produced from natural materials can be used as solid phase absorbant ${ }^{30}$.

Aim of this study is to develop a simple, rapid and reliable chromatographic method and to validate it in terms of linearity, repeatability, sensitivity, recovery, and robustness according to $\mathrm{ICH}$ guideline ${ }^{{ }^{31}}$. This simple, reliable and 
precise extraction method allowed the determination of human plasma PHT without any process of the deproteinization and derivatization. The method has a wide linear range that could be used efficiently in cases of therapeutic, subtherapeutic and overdose poisoning. It was used in a therapeutic drug monitoring study to determine the PHT levels in a plasma sample of 7 patients treated with PHT. Blood PHT concentrations of volunteers treated with PHT were determined by this method and the relationship between drug doses and blood results were statistically analyzed.

\section{METHODOLOGY}

\section{Chemicals and reagents}

The pharmaceutical standards of PHT (Figure 1-a) and DZP (Figure 1-b) were kindly donated by VEM Pharmaceuticals Company (Istanbul, Turkey) and Forensic Science Institute of Ankara University (Ankara, Turkey), respectively.

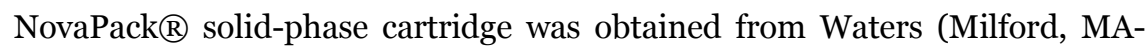
USA). HPLC grade acetonitrile and methanol were purchased from Sigma-Aldrich (St. Louis, MO, USA). Analytical grade potassium dihydrogen phosphate, dipotassium hydrogen phosphate and orthophosphoric acid were bought from Merck (Darmstadt, Germany). Membrane filters ( $0.45 \mu \mathrm{m}$ pore size) obtained from Millipore (Massachusetts, USA). Elga Purelab Water Purification System (Lane End, Buckinghamshire, UK) was used to obtain ultra-pure water.

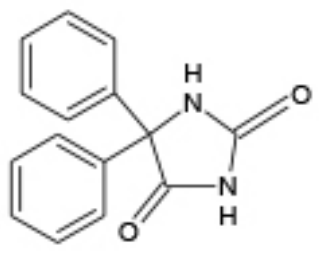

(a)

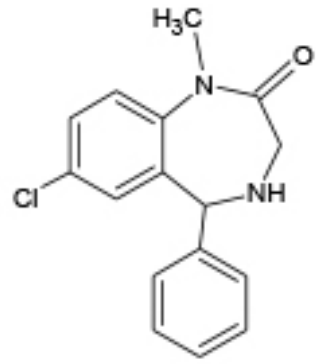

(b)

Figure 1. Chemical structures of PHT (a) and DZP (b). 


\section{Selection of internal standard chemical to be used in analysis}

Fluphenazine, carbamazepine, opipramol, imipramine, sildenafil, and DZP were tested for use as an ISTD. Although, carbamazepine and sildenafil showed good ultraviolet chromatographic characteristics, their retention times (tR) were unsuitable for the chromatographic analysis. Opipramol and imipramine didn't show good intensity at these chromatographic conditions. DZP's chromatographic characterics were so fine for using as ISTD. It showed very good intensity in the low concentrations. The obtained extraction recovery values were shown to be acceptable and reproducible. Also, it's separation sharpness and retention time has acceptable in the chromatogram. Furthermore, the coadministration of PHT and DZP in treatment is not frequently observed due to the different pharmacological effects. Thus, it was decided that the DZP should be selected as ISTD.

\section{Instrumentation and chromatographic conditions}

A Hewlett-Packard Agilent 1100 series (California, USA) high-performance liquid chromatography (HPLC) system which equipped a degasser (G1322A, Degasser), a gradient pump (G1311A, QuadPump), a column oven (G1316A, Colcom), a manual injector (Rheodyne 7725i) has $20 \mu \mathrm{L}$ loop volume, and an ultraviolet detector (G1314A, VWD) was used for separation and quantification. The integration of chromatographic data and system control (Palo Alto, USA) were achieved by Agilent Chemstation 08.03 software was used as. Analytical simultaneous separation was performed by a stainless steel Zorbax RP analytical column $(4.6 \mathrm{~mm}$ $\mathrm{x} 250 \mathrm{~mm}$ ) packed with $\mathrm{C}_{18}$ filling material has $5 \mu \mathrm{m}$ particle size (USA).

Optimum chromatographic conditions were set after performed for column, separation temperature, mobile phase content and detector wavelength. The better analytical seperation results obtained from the C18 RP Zorbax column ( $4.6 \times 250$ $\mathrm{m}, 5 \mu \mathrm{m}$ particle size) than the C18 RP Waters column (3.9 x $150 \mathrm{~mm}, 5 \mu \mathrm{m}$ particle size). The minimum back pressure and enough peak resolution for column were reached at $40^{\circ} \mathrm{C}$ in oven temperature. Although different wavelengths (246, 254, 270 and $290 \mathrm{~nm}$ ) were also used to determine PTH and DZP, the highest peak sharpness and the lowest interference were obtained from 220 and $230 \mathrm{~nm}$, respectively. The ultraviolet spectrums of PTH and DZP are given in Figure 2.

The mobile phase, composed with $10 \mathrm{mM} \mathrm{KH}_{2} \mathrm{PO}_{4}$ and $10 \mathrm{mM} \mathrm{K}_{2} \mathrm{HPO}_{4}$ that contain $0.1 \%$ triethylamine and acetonitrile $(60: 40, v / v)$, was filtered through a $0.45 \mu \mathrm{m}$ membrane (Illinois, USA) and before the using it was degassed by an ultrasonic bath, took at 30 minutes. Mobile phase's phosphate buffer was prepared with fresh ultrapure water and after adding triethylamine $\mathrm{pH}$ was ad- 
justed to 3.0 with $100 \mathrm{mM}$ ortophosphoric acid and mixed with acetonitrile. The mobile phase was isocratically applied to the column set at $40^{\circ} \mathrm{C}$ with 1.0 $\mathrm{mL} / \mathrm{min}$ constant flow. Determination of PTH concentration in the quality control and human blood samples were carried out to using linear regression of response (drug/ISTD peak area) versus DZP concentrations.
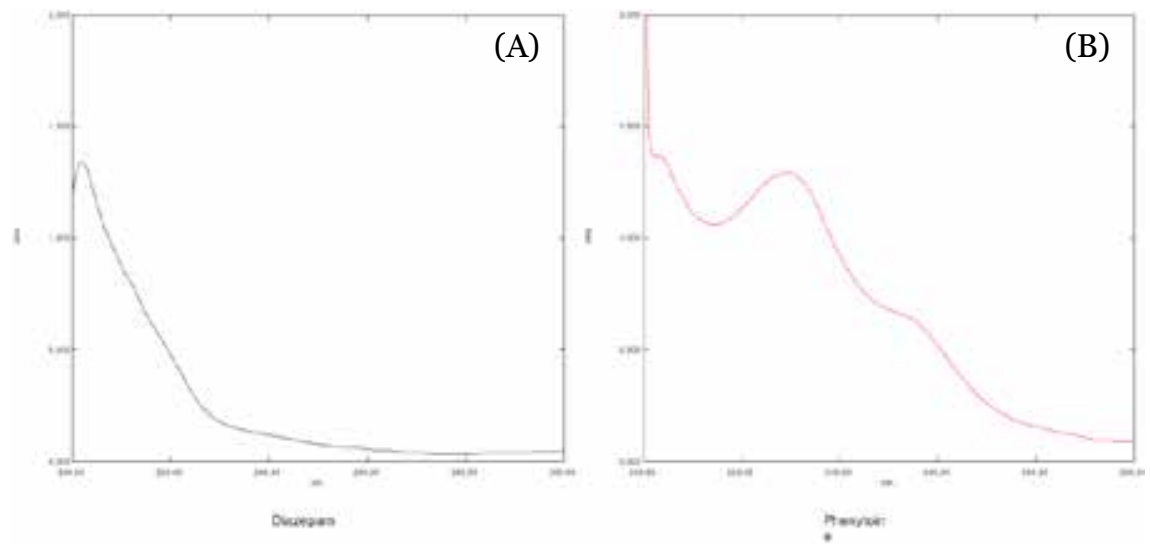

Figure 2. a. The ultraviolet spectrum of PHT. b. The ultraviolet spectrum of DZP used as an internal standard.

\section{Preparation of stock standard solutions and working standards}

Stock solution of PTH was prepared in methanol as $10 \mathrm{mg} / \mathrm{mL}$ and stored at $-20{ }^{\circ} \mathrm{C}$ until use. It had been observed that stable at least 1 months. Working solutions of PHT were prepared weekly from the main stock solution in methanol as $0.25,0.50,0.75,1.00,1.50,2.00,2.50 \mathrm{mg} / \mathrm{mL}$ concentrations. Working standards were prepared weekly, and used to spike blank plasma samples daily, prior to analysis. PHT dilutions were freshly prepared into the drug-free human plasma to provide concentrations of $5,10,15,20,30,40$ and $50 \mu \mathrm{g} / \mathrm{mL}$.

DZP main stock solution ( $1 \mathrm{mg} / \mathrm{mL}$ ) was prepared and used weekly with methanol to yield $20 \mu \mathrm{g} / \mathrm{mL}$ of DZP, in plasma. Likewise, plasma quality control standards spiked with 5,20 and $40 \mu \mathrm{g} / \mathrm{mL}$ of PHT were prepared to measure the repeatability values of the method. Also same protocol was used in preparation of limit of detection (LOD), quantification (LOQ), recovery and robustness test samples. 


\section{Preparation of quality control samples and real plasma samples}

Fresh the pool of human blood were prepared that collected from Sivas Cumhuriyet University, Blood Center of Medical School. These plasma samples have been used the forming of the quality control samples used during the development and validation process of this method. Also, the collected real patient blood centrifuged at $4000 \mathrm{rpm}$ for $5 \mathrm{~min}$ to separate the plasma. Quality control plasma and real patient plasma samples were stored at $-20^{\circ} \mathrm{C}$ until the analyses were carried out. Working solutions were checked chromatographically for purity before experiments, were utilized as quality control specimens and were checked for the stability before and after the injections of every sample set.

Waters (Milford, MA-USA) NovaPack $®$ cartridges (100 mg, $1 \mathrm{ml}$ ) were used for sample pretreatment. The SPE procedure was carried out on a glass SPE apparatus according to the following steps:

i. Cartridge adsorbent was conditioned with $1 \mathrm{~mL}$ acetonitrile;

ii. Equilibration was done with $1 \mathrm{~mL}$ water;

iii. Applying sample constituted in $500 \mu \mathrm{L}$ plasma with $10 \mu \mathrm{L}$ ISTD $(1 \mathrm{mg} / \mathrm{mL})$ standard solution and $10 \mu \mathrm{L}$ STD (for quality control samples) to cardridge;

iv. Washing (2x) with $1 \mathrm{~mL}$ water;

v. Eluting with acetonitrile for $2 \mathrm{~min}$ at $60 \mathrm{kPa}$ (to elute acetonitrile as completely as possible);

vi. Evaporating of the collecting extraction solvent under nitrogen;

vii. Injecting into the analysis system as a volume of $20 \mu \mathrm{L}$ after reconstitute of the residue in $500 \mu \mathrm{L}$ of the mobile phase.

\section{Method validation}

The developed analytical method was validated in terms of the specificity and selectivity, linearity, accuracy and precision, limit of detection (LOD) and limit of quantification (LOQ), recovery and robustness. Intraday and inter-day validation protocol were applied considering reproducibility of the method to obtain accurate and precise measurements in accordance with International Conference on Harmonization (ICH) Q2R1 guideline ${ }^{31}$.

\section{Specificity and selectivity}

The method showed excellent chromatographic specificity without endogenous interference at the retention times of PHT and DZP (5.8 and 10.0 min) in plasma. Representative chromatograms, which are blank (Figure 3-a), spiked (Fig- 
ure 3 -b) and real patient samples (Figure 3-c), were illustrate the high chromatographic resolution that conducted in 11 minutes.

\section{Linearity}

After chromatographic conditions were established, matrix-based calibration curves of PHT was plotted concentrations over the range $5-50 \mu \mathrm{g} / \mathrm{mL}$ versus peak-area ratios to the ISTD. The calibration points $(n=7)$, which were $5,10,15$, 20, 30, 40 and $50 \mu \mathrm{g} / \mathrm{mL}$ composed 3 individual replicates were prepared by standard addition method in plasma and injected to HPLC.

\section{Accuracy and precision}

The accuracy, defined as the relative error (RE\%) was calculated as the percentage difference between the added and found PHT quantity by 5 individual replicates both intraday and inter-day. The precision, defined as relative standard deviation (RSD\%), was calculated by five separate replicates of PHT both intraday and inter-day. Five replicate spiked samples were assayed intraday and inter-day at the three different concentrations $(5,20$ and $40 \mu \mathrm{g} / \mathrm{mL})$.
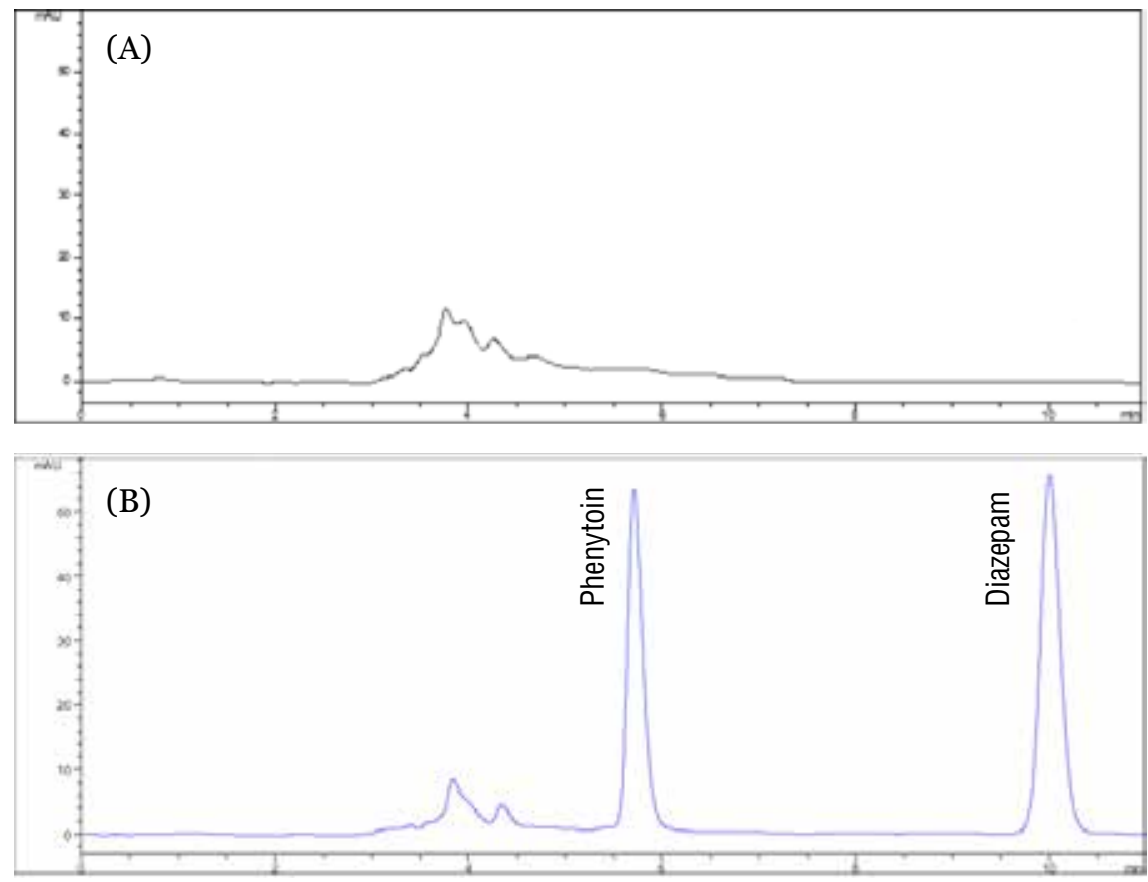


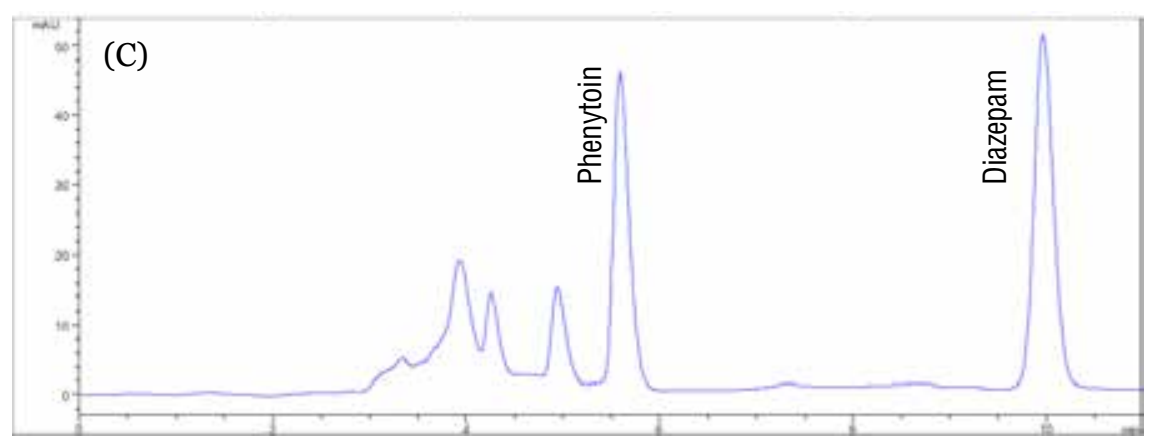

Figure 3. a. A chromatogram sample which belongs to blank plasma used to establish the quality control standards in validation studies. b. A chromatogram sample that contained PHT as $20 \mu \mathrm{g} / \mathrm{mL}$ which is prepared by standard addition method used as quality control sample. c. A chromatogram sample obtained form the real patient plasma

\section{Sensitivity}

The limit of detection (LOD) and limit of quantification (LOQ) were calculated according to the ICH recommendations based on standard deviation of the response and the slope of the calibration graph. $10 \mu \mathrm{g} / \mathrm{mL}$ was used as the lowest calibration point in sensitivity test of PHT.

$\mathrm{LOD}=3 \cdot 3 \frac{\sigma}{s} ; \mathrm{LOQ}=10 \frac{\sigma}{s}$

( $\sigma$ : The standard deviation of the response; $S$ : The slope of the calibration curve).

\section{Recovery}

The recovery of extraction procedures from human plasma was determined by comparing pre-extraction spikes with the post-extraction spiked ISTD. Five individual replicates of spiked samples at low, middle and high concentrations (5, 20 and, $40 \mu \mathrm{g} / \mathrm{mL}$, respectively) of PHT were prepared with and without ISTD. Extraction procedure was carried out as described before in sample preparation step.

\section{Robustness}

The robustness test was performed with $20 \mu \mathrm{g} / \mathrm{mL}$ of PHT, which is the approximate medium concentration of the calibration interval. The response of the method of changes in ultraviolet wavelength $( \pm 3 \mathrm{~nm})$, mobile phase flow rate $( \pm 0.1 \mathrm{~mL} / \mathrm{min})$, mobile phase solvent content $( \pm 5 \%)$ and column temperature $\left( \pm 5^{\circ} \mathrm{C}\right)$ was observed. 


\section{Collection of plasma samples}

Approximately $1 \mathrm{~mL}$ whole blood samples were taken from patients who had formed the steady-state concentration of the PHT in their plasma. As a rule, blood samples were taken from the patients after 12 hours the last drug administration. After it was centrifuged at 4000 rpm for 5 minutes, obtained individual $0.5 \mathrm{~mL}$ plasma samples stored in $-18^{\circ} \mathrm{C}$ until analyzed. The ethical permission of the this research was approved by the Clinical Research Ethics Committee which belong to Sivas Cumhuriyet University Medical School, with 2018-01/22 decision number on 10 January 2018 and was conducted in accordance with the Declaration of Helsinki and its subsequent revisions. Prior to inclusion in the research, the informed consent was obtained from all volunteers. Blood samples were obtained from 7 patients who were under the PHT treatment at the Sivas Cumhuriyet University, Medical School Department of Neurology. Blood samples collected in vacuum tubes containing $\mathrm{Na}_{2}$ EDTA were then centrifuged at 4000 rpm for 5 minutes on the same day. The supernatant (plasma) was transferred to the micro experiment tubes and it has been stored at the $-20{ }^{\circ} \mathrm{C}$ freezer until the analysis. Plasma PHT levels in patients were measured in less than one months.

Statistical analysis: All statistical analysis was performed using Statistical Package for the Social Sciences (SPSS) 22.o. Statistical analyses were performed using Student's t test for two independent means and correlation analysis- bivariate with a p value $<0.05$ considered to be statistically significant.

\section{RESULTS AND DISCUSSION}

\section{Method validation}

Validation procedures were conducted according to ICH-Q2R1 guideline during the whole test steps. ${ }^{31}$

\section{Linearity}

Calibration curves of PHT drawn at 7 points $(\mathrm{n}=3)$ between $5-50 \mu \mathrm{g} / \mathrm{mL}$ concentration versus the area of DZP as ISTD by the standard addition method showing excellent correlation with $\mathrm{r}^{2}=0.9939$, respectively (Table 1). The correlation of values obtained at the individual different 7 points was quite good. The linearity study was designed to covered sub-therapeutic, therapeutic and toxic drug levels of the drug. The wide linear range has also had a positive effect on the use of the method. Since, the obtained real blood results was shown very high standard deviation.

System suitability parameters show that it has a good resolution (Rs) and selectivity (a). Capacity factor and theoretical plate number $(N)$ show enough chro- 
matographic properties for a successful determination of PHT from plasma as it can follow in Table I.

Table I. Chromatographic characteristics and system suitability parameters of the method.

\begin{tabular}{|c|c|c|c|c|c|c|c|c|c|c|}
\hline Analyte & $\begin{array}{c}\text { Retention } \\
\text { time } \\
\text { (min) } \\
\text { tR }\end{array}$ & $\begin{array}{c}\text { Linear } \\
\text { range } \\
(\mu \mathrm{g} / \mathrm{mL})\end{array}$ & $\begin{array}{c}\text { Calibration } \\
\text { equation }\end{array}$ & $\begin{array}{c}\text { Correlation } \\
\text { coefficient } \\
\left(\mathrm{r}^{2}\right)\end{array}$ & $\begin{array}{c}\text { Capacity } \\
\text { factor } \\
\left(\mathbf{k}^{\prime}\right)\end{array}$ & $\begin{array}{l}\text { Theoretical } \\
\text { plate } \\
\text { number } \\
\text { (N) }\end{array}$ & $\begin{array}{c}\text { Selecitivity } \\
\text { (Separation) } \\
\text { factor } \\
\text { () }\end{array}$ & $\begin{array}{l}\text { Resolution } \\
\text { (Rs) }\end{array}$ & $\begin{array}{c}\text { LOD } \\
(\mu \mathrm{g} / \mathrm{mL})\end{array}$ & $\begin{array}{c}\mathrm{LOQ} \\
(\mu \mathrm{g} / \mathrm{mL})\end{array}$ \\
\hline PHT & 5.8 & $5-50$ & $\begin{array}{c}y=0.0345+ \\
0.0581\end{array}$ & 0.9939 & 1.0 & 1893 & 1.7 & 2.2 & 0.12 & 0.35 \\
\hline DZP & 10.0 & - & - & - & 2.5 & 10519 & - & - & - & - \\
\hline
\end{tabular}

Capacity factor $\left(\mathrm{k}^{\prime}\right)=\frac{t R-t \mathrm{O}}{t \mathrm{O}}$; Theoretical plate number $(N)=16\left(\frac{t R}{W t}\right)^{2}$; Resolution $\left(\mathrm{R}_{\mathrm{s}}\right)=$ $\frac{\sqrt{ } N}{4} \frac{\alpha-1}{\alpha} \frac{k}{k+1}$; Specificity factor $(\alpha)=\frac{k 2}{k 1}$. Abbreviations: $\mathrm{t}_{\mathrm{R}}$ : retention time of the analyte peak; to: retention time of mobile phase peak ; WT: peak width

\section{Sensitivity}

Limit of detection (LOD) and limit of quantification (LOQ) were determined based on the standard deviation of the response and the slope of the calibration curve ${ }^{31}(\mathrm{LOD}=3.3 \sigma / \mathrm{S}, \mathrm{LOQ}=10 \sigma / \mathrm{S}$ where $\sigma$ is the standard deviation of the response and $\mathrm{S}$ is the slope of the calibration curve). The results of LOD and LOQ values, which were obtained by the measurement of individual 10 quality control (QC) samples, demonstrated in Table I.

\section{Precision and accuray}

The data obtained from the accuracy and precision tests, performed in intraday and inter-day with quality control standards established in the blank plasma samples by standard addition method, showed low RSD\% values $\leq 7.5 \%$ and $\leq 7.94 \%$ for interday and intraday respectively and also low RE \% average values between $(-0.90)-2.49 \%$ for inter-day and (-0.93) - 0.22\% for intraday test values (Table II). The obtained repeatability results were show that, the method has excellent precision and accuracy values not only intraday but also inter-day analyses.

\section{Recovery}

Recovery test results which at done at 10,20 and $40 \mu \mathrm{g} / \mathrm{mL}$ were between 82.15\% and $101.06 \%$ and the results were given in Table II. The method has a highly successful analytical result with the average recovery of $90.36 \%$. Recov- 
ery values were obtained in the extraction procedure has demonstrated excellent efficiency. It was observed that extraction procedure was not complicated and also was not need to a sophisticated instruments.

\section{Robustness}

No significant changes in the analytical signals were observed upon changing ultraviolet wavelength value $( \pm 3 \mathrm{~nm})$, mobile phase flow rate $( \pm 0.1 \mathrm{~mL} / \mathrm{min}), \mathrm{mo}-$ bile phase organic solvent ingredient $( \pm 5 \%)$, and column temperature $\left( \pm 5^{\circ} \mathrm{C}\right)$. As well as, change of analysts, columns, sources of chemicals and/or solvents did not lead to significant changes in chromatographic signals and results, too. As it can follow in Table III, robustness experiment results demonstrated that the method has a high ability that created data of acceptable precision and accuracy.

Table II. Confidence parameters that including intraday, inter-day precision and accuracy and recovery values. These results were obtained from individual samples $(n=5)$ prepared as quality control samples in real plasma.

\begin{tabular}{|c|c|c|c|c|c|c|c|}
\hline \multirow{2}{*}{$\begin{array}{l}\text { Expected } \\
\text { conc. } \\
(\mu \mathrm{g} / \mathrm{mL})\end{array}$} & \multicolumn{3}{|c|}{ Intraday repeatability } & \multicolumn{3}{|c|}{ Inter-day repeatability } & \multirow[b]{2}{*}{$\begin{array}{c}\text { Recovery } \\
(\%)\end{array}$} \\
\hline & $\begin{array}{c}\text { Observed } \\
\text { conc. } \\
\mathcal{X}_{ \pm \mathrm{SD}} \\
(\mu \mathrm{g} / \mathrm{mL})\end{array}$ & $\begin{array}{l}\text { Precision } \\
\text { (RSD \%) }\end{array}$ & $\begin{array}{c}\text { Accuracy } \\
\text { (RE \%) }\end{array}$ & $\begin{array}{c}\text { Observed } \\
\text { conc. } \\
X_{ \pm} \text {SD } \\
(\mu \mathrm{g} / \mathrm{mL})\end{array}$ & $\begin{array}{l}\text { Precision } \\
\text { (RSD \%) }\end{array}$ & $\begin{array}{c}\text { Accuracy } \\
\text { (RE \%) }\end{array}$ & \\
\hline 10 & $\begin{array}{c}10.38 \pm \\
0.82\end{array}$ & 7.94 & 0.22 & $\begin{array}{c}10.25 \pm \\
0.27\end{array}$ & 2.59 & 2.49 & 82.15 \\
\hline 20 & $\begin{array}{c}19.99 \pm \\
0.92\end{array}$ & 4.48 & -0.05 & $\begin{array}{c}20.47 \pm \\
1.53\end{array}$ & 7.50 & -0.90 & 87.87 \\
\hline 40 & $\begin{array}{c}38.75 \pm \\
2.43\end{array}$ & 6.27 & -0.93 & $\begin{array}{c}39.69 \pm \\
0.92\end{array}$ & 2.33 & -0.78 & 101.06 \\
\hline
\end{tabular}


Table III. Robustness data of the described method representing as the RSD\% value. These results were obtained in the analysis of three variable points calculated by independent $(n=5)$ analyzes.

\begin{tabular}{|c|c|c|c|c|}
\hline Analytes & $\begin{array}{l}\text { Mobile phases } \\
\text { solvent content } \\
\quad( \pm 5 \%)\end{array}$ & $\begin{array}{c}\text { Ultraviolet } \\
\text { wavelength } \\
( \pm 3 \mathrm{~nm})\end{array}$ & $\begin{array}{c}\text { Flow rate } \\
( \pm 0.1 \mathrm{~mL} / \mathrm{min})\end{array}$ & $\begin{array}{l}\text { Column } \\
\text { temperature } \\
\left( \pm 5^{\circ} \mathrm{C}\right)\end{array}$ \\
\hline PHT $(20 \mu \mathrm{g} / \mathrm{mL})$ & 4.5 & 2.8 & 1.8 & 2.1 \\
\hline
\end{tabular}

\section{Stability}

The stability of QC plasma samples (10, 20 and $40 \mu \mathrm{g} / \mathrm{mL})$ and analytes in stock solutions under several conditions were assessed. Stability of the stock solutions at room temperature was evaluated with 1, 2, 3 and 4 week periods. The stability test of freeze-thaw was executed by three QC samples after operating five repeated freeze-thaw period. The stability test of long-term was carried out for 1, 2 and 3 months using QC samples maintained at $-20^{\circ} \mathrm{C}$. Neither significant decrease nor degradation were observed in the concentration of VPA in three different conditions. The relative standard deviation in all samples was less than $5.3 \%$.

\section{Measurement of PHT levels in patient plasma samples}

The developed HPLC method was used to monitoring of the PHT levels in plasma samples taken from 7 patients who receiving PHT orally between 100 and $300 \mathrm{mg} /$ day. Plasma samples were prepared according to the extraction method described previously. None of these samples showed any problem for the quantification of the analytes, additionally, peak purity showed that no analytical interference was encountered from endogenous substances. The daily used PHT amounts, PHT plasma levels, its dose-proportional levels and the descriptive statistical analysis for the obtained data are given in Table IV. 
Table IV. The samples included to the analysis, daily PHT doses, plasma and dose proportionally plasma PHT concentrations.

\begin{tabular}{|c|c|c|c|c|c|}
\hline \multirow{2}{*}{$\begin{array}{l}\text { Patient } \\
\text { sample } \\
\text { number }\end{array}$} & \multirow{2}{*}{$\begin{array}{c}\text { PHT } \\
\text { Dose } \\
\text { (mg/day) }\end{array}$} & \multicolumn{2}{|c|}{ Method-1st } & \multicolumn{2}{|c|}{ Method-2 ${ }^{\text {nd }}$} \\
\hline & & $\begin{array}{c}\text { Plasma PHT } \\
\text { concentration } \\
(\mu \mathrm{g} / \mathrm{mL})\end{array}$ & \begin{tabular}{|c|} 
Plasma PHT \\
concentration/ \\
Dose \\
$(\mu \mathrm{g} / \mathrm{mL} / \mathrm{g})$ \\
\end{tabular} & \begin{tabular}{|c|} 
Plasma PHT \\
concentration/ \\
Dose \\
$(\mu \mathrm{g} / \mathrm{mL} / \mathrm{g})$
\end{tabular} & $\begin{array}{c}\text { Plasma PHT } \\
\text { concentration/ } \\
\text { Dose } \\
(\mu \mathrm{g} / \mathrm{mL} / \mathrm{g})\end{array}$ \\
\hline PHT-01 & 300 & 6.87 & 22.89 & 3.88 & 12.93 \\
\hline PHT-02 & 100 & 14.30 & 143.00 & $<2.5$ & $<25.00$ \\
\hline PHT-03 & 300 & 18.50 & 61.66 & 10.6 & 35.33 \\
\hline PHT-04 & - & 7.07 & - & - & - \\
\hline PHT-05 & 300 & 18.76 & 62.52 & 11.0 & 36.67 \\
\hline PHT-06 & 200 & 1.12 & 5.59 & $<2.5$ & $<12.50$ \\
\hline PHT-07 & - & ND & - & - & - \\
\hline \multicolumn{2}{|c|}{ Average } & 9.52 & 59.13 & 8.49 & 28.31 \\
\hline \multicolumn{2}{|c|}{ SD } & 7.78 & 52.99 & 4.00 & 13.34 \\
\hline \multicolumn{2}{|c|}{$\mathrm{RSD} \%$} & 81.74 & 89.61 & 47.10 & 47.11 \\
\hline
\end{tabular}

Note: Method $-1^{\text {st }}$ refer to our developed and validated analysis method and Method $-2^{\text {nd }}$ refers to the analysis method used routinely from Hospital.

Same plasma samples were analyzed with the homogeneous enzym immunoassay (EMIT) tecnique. The method used for routine therapeutic drug monitoring analysis of PTH was established by Sivas Cumhuriyet University, Faculty of Medicine. According to obtained patient results, LOQ of this method was given $2.5 \mu \mathrm{g} / \mathrm{mL}$. However, this method does not give definite PTH plasma levels which may be observed in low levels due to polymorphism and compliance problem to PTH. The correlation between our method and the other immunoassay based method was $1.00(\mathrm{p}<0.01)$ and a very strong correlation was observed. On the other hand, when the obtained results which got from two different methods were evaluated, it was observed that plasma results showed that the different PTH values. The difference between plasma PTH results obtained by two methods was found to be statistically not significant ( $p>0.05$ ). 
As a sample, a volunteer patient chromatogram was given in Figure 3-c which a representative of the real plasma sample separation. As can be clearly seen, no interference was observed that could affect the analysis. All blood samples were successfully pretrated to the analyses and their owned PTH quantities were measured properly. Although these patients undergoing plasma drug monitoring were in multidrug treatment, as can be clearly seen from the sample chromatogram, no interference was observed that could affect the analysis not only as pharmaceutical but also endogenous from plasma.

There was 7 voluntary patients' blood samples, who have been treated orally PTH between 100 and $300 \mathrm{mg} /$ day, and the average dose/day of PTH was 240 $\mathrm{mg} /$ day. The detected average blood PTH level was $9.57 \mu \mathrm{g} / \mathrm{mL}(7.71 \pm 80.58$, $\mathrm{SD} \pm \mathrm{RSD} \%) . \mathrm{SD}$ and RSD values were higher than expected due to the deviation between plasma PTH results. Since the therapeutic range of the PTH is so narrow and its have serious toxicological risks, the investigation of blood values is of great importance. For this reason, the drug level monitorization is suggested during treatment with this drug. More interesting results were observed in the dose-proportional results of plasma level of PTH with values of $59.13 \mu \mathrm{g} /$ $\mathrm{mL} / \mathrm{g} \pm 52.99$ (89.61) (mean $\pm \mathrm{SD}$ (RSD\%)). The unexpected high levels standard deviation (SD\%) and also RSD\% emerged in the result. The metabolic differences of enzymes who responsible for the metabolism of this drug between individuals are thought to play an important role in the emergence of this difference. In addition, the bioavailability of this drug may negatively be affected by the first pass effect. This situation leads to a reduction in the pharmacological and pharmacodynamic effect expected from the PTH treatment.

Recommended blood plasma values for the treatment with PTH are between 10 and $20 \mu \mathrm{g} / \mathrm{mL}$. The result of the study showed that out of 4 in 7 patients treated with PTH (57.14\%) had plasma concentrations below these values. However, this is very important because the patients show that they continue to undergo treatment for PTH at a lower level than they need. This means that, despite drug intake, serious symptoms of the disease cannot be prevented. In addition, it is toxicologically important that no overdose was observed for PTH in any of the plasma of the 7 patients monitored. This situation is very important in terms of public health because the treatment has serious toxicological risks.

It was thought that the effect of biotransformation enzymes on PTH was an important factor in the emergence of this unexpected result. On the other hand, multidrug therapy is thought to be another important cause of the outcome. Consequently, this result showed that the importance and necessity during the treatment of the TDM. 
The study published by Bugamelli et al. (2002) phenytoine and totaly six antieplieptic and two sellected metabolites were pretreated with two different procedures which are protein precipitation and solid-phase extraction were tested in this study and then obtained extracts were determined by HPLC-DAD method ${ }^{12}$. In this research, $250 \mu \mathrm{L}$ plasma sample was used in the analysis and instrument was calibrated with quality control samples which were prepared in real plasma. Seperation was achieved with the mixture of methanol, acetonitrile and $15 \mathrm{mM}$ phosphate buffer containing $0.63 \%(\mathrm{pH} 3.0)$ triethylamine (19.2:16.8:64.0, (v/v/v)) by a C18 column ( $150 \times 4.0 \mathrm{~mm}$, i.d. $4.5 \mu \mathrm{m}$ ). Altrough, LOQ was detected as $0.2 \mu \mathrm{g} /$ $\mathrm{mL}$, correlatlion coefficiency was foud 0.998. Linearity study was applied between 4 and $40 \mu \mathrm{g} / \mathrm{mL}$. PTH retention time (Rt) was approximately 11.0. Also, althought recovery was determined between 94 to $101 \%$, precision was detected as $\leq 10.3$.

Another HPLC-DAD based study was carried out by Dalmora et al. (2009) ${ }^{13}$. In study, human plasma samples $(300 \mu \mathrm{L})$ were prepared with liquid-liquid extraction method and isocreatic seperation was achieved with a reverse phase C12 column ( 150 x $4.6 \mathrm{~mm}$ i.d.) with a mobile phase constituted with water: acetonitrile: methanol (58.8:15.2:26, v/v/v). Detector was set at $205 \mathrm{~nm}$. Phenobarbital was used as an internal standard. Chromatographic run time was $12 \mathrm{~min}$. Instrument calibrated with quality control samples prepared between 50 and $2500 \mathrm{ng} / \mathrm{mL}$ PTH. Precision was $\leq 4.48$ RSD\% and accuracy was between 98.71 to $100.17 \%$. This developed method was succesfully applied to 22 volunteers' blood for the bioequvalance study for evaluation of two tablets formulation.

Khedr et al. $2008{ }^{14}$ was developed a new HPLC-DAD method in rabbit plasma. Sildenafil was used as an internal standard. Extraction was achieved with a based on solid-phase method and detector set at $220 \mathrm{~nm}$. Isocreatic seperation was achieved with Agilent Zorbax Extended C18 column (150 mm $\times 4.6 \mathrm{~mm}$ internal diameter) and mobile phase which consist of $29 \%$ acetonitrile and $71 \%$ sodium acetate solution (0.02 M, pH 4.6). Method was linear between 0.15 to $39 \mu \mathrm{g} / \mathrm{mL}$ and LOD was found as $0.15 \mu \mathrm{g} / \mathrm{mL}$. Recovery was found $101.88 \%$. The mobile phase consist of $29 \%$ acetonitrile and $71 \%$ sodium acetate solution (0.02 M).

In another study, Maya et al. (1992), a new method was developed was described for determination of PTH in plasma and urine and its metabolite 5-(4-hydroxyphenyl)-5-phenylhydantoin, in urine ${ }^{15}$. Seperation of extracts a Nova-Pak RP-C18 column was achieved in the chromatographic seperation using a mobile phase consisting of methanol-water-tetrahydrofuran (40:60:4, $\mathrm{v} / \mathrm{v} / \mathrm{v}$ ) with UV detection at $230 \mathrm{~nm}$. The method established to determination of PHT in plasma and urine was linear between 0.4-4.0 $\mu \mathrm{g} / \mathrm{mL}$ and 0.1-1.0 $\mu \mathrm{g} /$ $\mathrm{mL}$. Precision showed a good value which is RSD\% $\leq 4.49 \%$. 
Guan et al. (2000), ${ }^{16}$ is described a reliable and sensitive method for the extraction and quantification of phenytoin (5,5'-diphenylhydantoin), its major metabolite, 5-(p-hydroxyphenyl)-5-phenylhydantoin (p-HPPH) and minor metabolite, 5-(m-hydroxyphenyl)-5-phenylhydantoin (m-HPPH) in equine urine and plasma. Solid-phase extraction (SPE), liquid-liquid extraction (LLE), enzyme hydrolysis (EH) methods were used in the sample preparation step and high-performance liquid chromatography (HPLC) was used for determination of extracts.

Bahal and Nahata (1993) ${ }^{17}$ was described a new method for determination of both phenytoin and its major metabolite, 5-(p-hydroxyphenyl)-5-phenylhydantoin (p-HPPH) in urine. In this method, a Water $10 \mu \mathrm{m} \mu$ Bondapak C-18 column was used in the sample extraction step, a mobile phase containing $45 \%$ acetonitrile and $55 \%$ distilled water was used in the seperation, and the ultraviolet detector set at $230 \mathrm{~nm}$ was used for the quantitative determination. Analitical run time was $\leq 9.0 \mathrm{~min}$. As an internal standard, 5-(4-methylphenyl)5-phenyl-hydantoin was used. The correlation coefficients was 0.999. Accuracy was between 94.3 and 108.8 RE\%. Precision (RSD\%) was $\leq 5.0 \%$.

The precision ( $\leq 7.94$ RSD\%) and accuracy ((-0.93) and 2.49 RE\%) result of the method showed that it has enough repeatability values. Exactly, the observed values from the accuracy tests were excellent. The obtained results from the method repeatability increase the reliability of the performed analyses. The sample extraction, has single step, was simple and rapid, which provided the excellent reliable recovery values between $82.15 \%$ and $101.06 \%$ (90.36 \pm 9.70 , $\bar{x}_{ \pm \mathrm{SD}}$ ). This method has some attractive properties which are the simplicity of sample preparation protocol although it was a solid phase method; relatively short analysis time (11 $\mathrm{min}$ ) and favourable LOQ value. Furthermore, our analysis method stands out from published methods with remarkable accuracy and recovery values. In addition, the robustness and stability tests performed demonstrated the strength of the method against changing conditions which ability may effect seriously the analysis. Almost all of the patients included in this study were using at least one other drug in addition to PHT, some of which are known to be under heavy drug treatment with multidrug therapy. On the other hand, this did not cause a chromatographic problem in any blood sample and no problem in quantification. Thus, the test results clearly demonstrated that this developed assay method is fast, precise and reliable for plasma PHT analyzes.

We strongly recommended this validated method to be used in routine therapeutic drug analysis of PHT and also it can be adapted for monitoring of overdose/poisoning with this drug. Furthermore, since the method is established in 
the range of 5 to $50 \mu \mathrm{g} / \mathrm{mL}$, it can be used in overdose and suicide cases with PHT as well as in the detection of compliance problems. The proposed method can be easily applied in routine TDM studies of PHT, also it can be preferred in bioequivalence studies, pharmacovigilance and pharmacokinetics studies.

In our study, it was observed that both plasma-PHT levels and plasma-PHT recorrected according to daily drug doses $(\mu \mathrm{g} / \mathrm{mL} / \mathrm{g})$ were observed very high RSD\% results which are 80.58 and $89.61 \%$, respectively. These results are both pharmacological and toxicologically significant and have the potential to cause serious health problems.

Since these observed unexpected plasma PHT concentrations are thought to be related to the polymorphism of the enzymes $\mathrm{CYP}_{2} \mathrm{C} 9$ and $\mathrm{CYP}_{2} \mathrm{C} 19$ responsible for the biotransformation of PHT, it is planned to investigate the polymorphisms of the respective enzymes in the collected blood samples and investigate its relationship with the plasma results obtained.

\section{ACKNOWLEDGEMENTS}

This research was partly supported by Sivas Cumhuriyet University, Faculty of Pharmacy. The authors kindly thanks to VEM Pharmaceuticals and Forensic Science Institute of Ankara University for the donation of PHT and DZP chemical standards, respectively. The author would like to thank to Sivas Cumhuriyet University, Research Center of Medical School (CÜTFAM) kindly for the excellent and open collaboration.

\section{CONFLICT OF INTEREST STATEMENT}

None of the authors of this article have a financial or personal relationship with each other or organizations that may inappropriately affect or bias the content of the paper. All authors declare that, there is no conflict of interest. 


\section{REFERENCES}

1. Begley, C. E.; Famulari, M.; Annegers, J. F.; Lairson, D. R.; Reynolds, T. F.; Coan, S.; Dubinsky, S.; Newmark, M. E.; Leibson, C.; So, E. L.; Rocca, W. A. The Cost of Epilepsy in the United States: An Estimate from Population-Based Clinical and Survey Data. Epilepsia. 2ooo, 41, 342-351.

2. Panomvana, D.; Khummuenwai, N; Sra-ium, S.; Towanabut, S. Steady-State Serum Phenytoin Concentrations After Nasogastric Tube Administration of Immediate-Release Phenytoin Tablets and Extended-Release Phenytoin Capsules: An Open-Label, Crossover, Clinical Trial. Curr. Ther. Res. Clin. Exp. 2007, 68, 325-337.

3. Schmidt, D.; Schachter, S.C. Drug Treatment of Epilepsy in Adults. BMJ. 2014, 348, g254.

4. Temiz, C.; Temiz, P.; Demirel, A.; Sayin, M.; Umur, A.S.; Ozer, F.D. Effect of Sodium Phenytoin Concentration on Neural Tube Development in the Early Stages of Chicken Embryo Development. J. Clin. Neurosci. Off. J. Neurosurg. Soc. Australas. 2009, 16, 307-311.

5. Aronson, J. K.; Hardman, M.; Reynolds, D. J. ABC of Monitoring Drug Therapy. Phenytoin. BMJ. 1992, 305, 1215-1218.

6. Lin, P. C.; Hsieh, Y. H.; Liao, F. F.; Chen, S. H. Determination of Free and Total Levels of Phenytoin in Human Plasma from Patients with Epilepsy by MEKC: An Adequate Alternative to HPLC. Electrophoresis. 2010, 31, 1572-1582.

7. Wu, M. F.; Lim, W.H. Phenytoin: A guide to Therapeutic Drug Monitoring, Proc. Singapore Healthc. 2013, 22,198-202.

8. Ohnmacht, C. M.; Chen, S.; Tong, Z.; Hage, D. S. Studies by Biointeraction Chromatography of Binding by Phenytoin Metabolites to Human Serum Albumin. J. Chromatogr. B, Anal. Technol. Biomed. Life Sci. 2006, 836, 83-91.

9. Domingues, D. S.; Pinto, M. A. L.; De Souza, I. D.; Hallak, J. E. C.; Crippa, J. A. de S.; Queiroz, M. E. C. Determination of Drugs in Plasma Samples by High-Performance Liquid Chromatography-Tandem Mass Spectrometry for Therapeutic Drug Monitoring of Schizophrenic Patients. J. Anal. Toxicol. 2016, 40, 28-36.

10. Deeb, S.; McKeown, D.A.; Torrance, H.J.; Wylie, F.M.; Logan, B.K.; Scott, K.S.. Simultaneous Analysis of 22 Antiepileptic Drugs in Postmortem Blood, Serum and Plasma Using LC-MS-MS with a Focus on their Role in Forensic Cases. J. Anal. Toxicol. 2014, 38, 485-494.

11. Datar, P.A. Quantitative Bioanalytical and Analytical Method Development of Dibenzazepine Derivative, Carbamazepine: A Review. J. Pharm. Anal. 2015, 5, 213-222.

12. Bugamelli, F.; Sabbioni, C.; Mandrioli, R.; Kenndler, E.; Albani, F.; Raggi, M.A. Simultaneous Analysis of Six Antiepileptic Drugs and Two Selected Metabolites in Human Plasma by Liquid Chromatography After Solid-Phase Extraction. Anal. Chim. Acta. 2oo2, 472, 1-10.

13. Dalmora, S. L.; Nugueira, D. R.; Londero, L. F.; Santana, D. P.; Gonçalves, T. M. Determination of Phenytoin in Human Plasma by a Validated Liquid Chromatography Method and its Application to a Bioequivalence Study. Lat. Am. J. Pharm. 2oo9, 28, 247-253.

14. Khedr, A.; Moustafa, M.; Abdel-Naim, A. B.; Alahdal, A.; Mosli, H. High-Performance Liquid Chromatographic Method for Determination of Phenytoin in Rabbits Receiving Sildenafil. Anal. Chem. Insights. 20o8, 3, 61-67.

15. Maya, M. T.; Farinha, A. R.; Lucas, A.M.; Morais, J. Sensitive Method for the Determination of Phenytoin in Plasma, and Phenytoin and 5-(4-hydroxyphenyl)-5-Phenylhydantoin in Urine by High-Performance Liquid Chromatography. J. Pharm. Biomed. Anal. 1992, 1, 1001-1006. 
16. Guan, F.; Uboh, C. E.; Soma, L. R.; Birks, E. K.; Teleis, D.; Rudy, J. A.; Watson, A. O., Tsang, D. S. Quantification of Phenytoin and its Metabolites in Equine Plasma and Urine Using High-Performance Liquid Chromatography. J. Chromatogr. B. Biomed. Sci. Appl. 2ooo, 746, 209-218.

17. Bahal, N.; Nahata, M.C. Determination of Phenytoin and Its Major Metabolite, 5-(pHydroxyphenyl)-5-phenylhydantoin in Urine by High-Performance Liquid Chromatography, J. Liq. Chromatogr. 1993, 16, 1135-1142.

18. Castro, A.; Ibanez, J.; DiCesare, J.L.; Adams, R.F.; Malkus, H. Comparative Determination of Phenytoin by Spectrophotometry, Gas Chromatography, Liquid Chromatography, Enzyme Immunoassay, and Radioimmunoassay. Clin. Chem. 1978, 24, 710-713.

19. Hara S.; Hagiwara, J.; Fukuzawa, M.; Ono, N.; Kuroda, T. Determination of Phenytoin and Its Major Metabolites in Human Serum by High-Performance Liquid Chromatography with Fluorescence Detection, Anal. Sci. 1999, 15, 371-375.

20. Peat J.; Frazee, C.; Garg, U. Quantification of Free Phenytoin by Liquid Chromatography Tandem Mass Spectrometry (LC/MS/MS). Methods Mol. Biol. 2016, 1383, 241-246.

21. Villanelli, F.; Giocaliere, E.; Malvagia, S.; Rosati, A.; Forni, G.; Funghini, S.; Shokry, E.; Ombrone, D.; Della Bona, M.L.; Guerrini, R.; Marca, G. la. Dried Blood Spot Assay for the Quantification of Phenytoin Using Liquid Chromatography-Mass Spectrometry. Clin. Chim. Acta. 2015, 440, 31-35.

22. Roy, S. M. N.; Yetal, S. M.; Vaidya, V. V.; Joshi, S. S. Determination and Quantification of Phenytoin in Human Plasma by Liquid Chromatography with Electrospray Ionization Tandem Mass Spectrometry, E-Journal Chem. 2oo8, 5, 169-176.

23. Bardin, S; Ottinger, J. C.; Breau, A. P., O'Shea, T. J. Determination of Free Levels of Phenytoin in Human Plasma by Liquid Chromatography/Tandem Mass Spectrometry, J. Pharm. Biomed. Anal. 2000, 23, 573-579.

24. Hösli, R.; Tobler, A.; König, S.; Mühlebach, S. A Quantitative Phenytoin GC-MS Method and Its Validation for Samples From Human ex situ Brain Microdialysis, Blood and Saliva Using Solid-Phase Exraction. J. Anal. Toxicol. 2013, 37, 102-109.

25. Khoubnasabjafari, M.; Salari, R; Samadi, A.; Jouyban-Gharamaleki, V.; Jouyban, A. Colorimetric Determination of Phenytoin Using Indoxyl Sulfate Capped Silver Nanoparticles, Anal. Methods. 2019, 11, 3324-3330.

26. Tang, H. T.; Halsall, H. B.; Heineman, W. R. Electrochemical Enzyme Immunoassay for Phenytoin by Flow Injection Analysis Incorporating a Redox Coupling Agent. Clin. Chem. 1991, 37, 245-248.

27. Othman, S.; al-Turk, W. A.; Awidi, A. S.; Daradkeh, T. K.; Shaheen, O. Comparative Determination of Phenytoin in Plasma by Fluorescence Polarization Immunoassay and High Performance Liquid Chromatography. Drug Des. Deliv. 1987, 2, 41-47.

28. Queiroz, R. H. C.; Bertucci, C.; Malfará, W. R.; Dreossi, S. A. C.; Chaves, A. R; Valéri, D. A. R.; Queiroz, M. E. C. Quantification of Carbamazepine, Carbamazepine-10,11-epoxide, Phenytoin and Phenobarbital in Plasma Samples by Stir Bar-Sorptive Extraction and Liquid Chromatography, J. Pharm. Biomed. Anal. 2oo8, 48, 428-434.

29. Rani, S.; Malik, A. K. A Novel Microextraction by Packed Sorbent-Gas Chromatography Procedure for the Simultaneous Analysis of Antiepileptic Drugs in Human Plasma and Urine. J. Sep. Sci. 2012, 35, 2970-2977.

30. Filiz, Z; Oymak, T.; Dural, E. Determination of Synthetic Colorants in Cosmetic Products 
by Reversed-Phase High-Performance Liquid Chromatography Coupled with Diode-Array Detector, J. Res. Pharm. 2019, 23, 1048-1059.

31. ICH Topic Q2 (R1) Validation of Analytical Procedures: Methodology Text and Methodology (International Conference on Harmonization of Technical Requirements for Registration of Pharmaceuticals for Human Use, 2005. 